\title{
Determination of Iron in Dietary Supplements by Voltammetric Analysis at an Iodine-Coated Polycrystalline Platinum Electrode
}

\author{
Mohammad Amayreh and Mohammed Khair Hourani* \\ Electrochemistry Research Laboratory, Department of Chemistry, The University of Jordan, Amman \\ 11942, Jordan \\ *E-mail: $\underline{\text { mhourani@ju.edu.jo }}$
}

doi: $10.20964 / 2018.01 .81$

Received: 2 March 2017 / Accepted: 7 November 2017 / Online Published: 16 December 2017

\begin{abstract}
An iodine-coated polycrystalline platinum electrode was applied to analysis of iron in dietary supplements. The developed method is based on scanning the potential of the iodine-coated polycrystalline platinum electrode between the hydrogen evolution limit $(-0.25 \mathrm{~V})$ and a potential lower than the threshold of iodine desorption from the platinum surface (ca. $+0.80 \mathrm{~V})$. An anodic peak centered nearly at $0.56 \mathrm{~V}$ is assigned to $\mathrm{Fe}(\mathrm{II})$ oxidation to $\mathrm{Fe}(\mathrm{III})$. The anodic peak current ( $\mathrm{i}_{\mathrm{p}}$ ) showed an excellent linearity $\left(\mathrm{R}^{2}=0.995\right)$ with the concentration of $\mathrm{Fe}^{2+}$ within a concentration range from 4$500 \mathrm{ppm} \mathrm{Fe}$. The anodic peak current, as expected for a diffusion controlled process showed a linear relationship with the square root of the scan rate $\left(\mathrm{R}^{2}=0.999\right)$. The limit of detection (based on $\mathrm{S} / \mathrm{N}=3$ ) for the developed method is $2.34 \mathrm{ppm}$ while the limit of quantitation (based on $\mathrm{S} / \mathrm{N}=10$ ) is $7.8 \mathrm{ppm}$. The effect of potential interferences like calcium, magnesium, zinc, selenium, copper, manganese, chromium, molybdenum, vanadium was investigated. Silver and copper were the only ones among the investigated elements which showed resolved peaks from those of $\mathrm{Fe}$ (II) within the accessible potential window of the iodine-coated platinum electrode. Analysis of real samples and application of statistical tests to the results indicated the absence of systematic error in the results and the validity of the null hypothesis, i.e., there is no significant difference between the nominal values reported by the manufacturers and our results at $\mathrm{p}=0.05$.
\end{abstract}

Keywords: determination of iron, idoine-coated platinum, platinum modified electrode, dietary supplements.

\section{FULL TEXT}

(C) 2018 The Authors. Published by ESG (www.electrochemsci.org). This article is an open access article distributed under the terms and conditions of the Creative Commons Attribution license (http://creativecommons.org/licenses/by/4.0/). 